\title{
Diagnostic delay for giant cell arteritis - a systematic review and meta-analysis
}

\author{
James A. Prior ${ }^{1 *}$, Hoda Ranjbar ${ }^{1}$, John Belcher ${ }^{1}$, Sarah L. Mackie, ${ }^{2,3}$, Toby Helliwell $^{1}$, Jennifer Liddle ${ }^{1,4}$ \\ and Christian D. Mallen ${ }^{1}$
}

\begin{abstract}
Background: Giant cell arteritis (GCA), if untreated, can lead to blindness and stroke. The study's objectives were to (1) determine a new evidence-based benchmark of the extent of diagnostic delay for GCA and (2) examine the role of GCA-specific characteristics on diagnostic delay.

Methods: Medical literature databases were searched from inception to November 2015. Articles were included if reporting a time-period of diagnostic delay between onset of GCA symptoms and diagnosis. Two reviewers assessed the quality of the final articles and extracted data from these. Random-effects meta-analysis was used to pool the mean time-period (95\% confidence interval (Cl)) between GCA symptom onset and diagnosis, and the delay observed for GCA-specific characteristics. Heterogeneity was assessed by $P^{2}$ and by $95 \%$ prediction interval (PI).

Results: Of 4128 articles initially identified, 16 provided data for meta-analysis. Mean diagnostic delay was 9.0 weeks ( $95 \% \mathrm{Cl}, 6.5$ to 11.4$)$ between symptom onset and GCA diagnosis ( $P^{2}=96.0 \% ; P<0.001 ; 95 \% \mathrm{Pl}, 0$ to 19.2 weeks). Patients with a cranial presentation of GCA received a diagnosis after $7.7(95 \% \mathrm{Cl}, 2.7$ to 12.8$)$ weeks $\left(P^{2}=98.4 \%\right.$; $P<0.001 ; 95 \% \mathrm{Pl}, 0$ to 27.6 weeks) and those with non-cranial GCA after 17.6 (95\% Cl, 9.7 to 25.5) weeks $\left(P^{2}=96.6 \% ; P<0.001 ; 95 \% \mathrm{Pl}, 0\right.$ to 46.1 weeks $)$.

Conclusions: The mean delay from symptom onset to GCA diagnosis was 9 weeks, or longer when cranial symptoms were absent. Our research provides an evidence-based benchmark for diagnostic delay of GCA and supports the need for improved public awareness and fast-track diagnostic pathways.
\end{abstract}

Keywords: Diagnostic delay, Giant cell arteritis, Meta-analysis, Systematic review

\section{Background}

Giant cell arteritis (GCA) is the most common form of medium and large-vessel vasculitis [1]. Inflammation typically affects head and neck arteries, including the superficial temporal and posterior ciliary arteries [2]. Symptoms are caused by local vascular ischaemia often combined with cytokine-mediated features [3]. Symptoms may include headache, jaw claudication, transient visual loss, scalp tenderness, and limb claudication [4]. If GCA is untreated, permanent visual loss or stroke may ensue [5], other potential complications include aortic aneurysm, dissection and rupture [6].

\footnotetext{
* Correspondence: j.a.prior@keele.ac.uk

${ }^{1}$ Research Institute for Primary Care and Health Sciences, Keele University, ST5 5BG Newcastle, UK

Full list of author information is available at the end of the article
}

In the UK, 10 people per 100,000 are reported to be affected by GCA [7], with women being three times more likely to be affected than men [8]. GCA occurs after age 50 and its incidence increases with age [7,9], with a strong association with polymyalgia rheumatica (PMR). High-dose glucocorticoids are a highly effective treatment for GCA [10]. Early diagnosis and treatment are believed to be crucial since visual loss may occur in up to $15-20 \%$ of patients with GCA before treatment is commenced, while visual loss after the first 1-2 weeks of treatment is very rare [11].

Diagnosis of GCA in primary care remains difficult. Primary care physicians are faced with the frequently non-specific nature of many early symptoms of GCA, its relative rarity and a high prevalence of similar symptoms in the general consulting population [3, 12]. Delay to diagnosis is therefore not unusual $[13,14]$. Delay may also occur as patients may not be aware of the 
significance of GCA symptoms, such as jaw claudication and temporal artery abnormality, and therefore do not seek healthcare promptly [15].

The importance of understanding the extent of diagnostic delay, and the reasons associated with delay, has been widely investigated by those seeking to improve care for patients with other conditions, including ischaemic heart disease and cancers [16, 17]. This has led to the development of public health interventions to raise awareness $[18,19]$. For GCA, a secondary care 'fasttrack' referral pathway, combined with GP education, reported a significant reduction in the number of patients experiencing permanent sight loss compared to those going through usual care. Though multifactorial, the reduction in diagnostic delays played a role in achieving this reduction in sight loss [20].

Our aim was to systematically review the existing literature reporting the extent of delay in receiving a GCA diagnosis. Our specific objectives were (1) to determine a new evidence-based benchmark of the extent of this delay by pooling the mean time-periods between GCA symptom onset and diagnosis of GCA and (2) to examine the role of GCA-specific characteristics on delay.

\section{Methods}

A systematic review and meta-analysis of research literature was conducted. Medical bibliographic databases were searched to identify articles containing data on the mean time-period between the onset of GCA symptoms and GCA diagnosis. Meta-analysis was used to determine a pooled estimate of the time-period of diagnostic delay and analysed with regards to different GCA-specific characteristics.

\section{Data sources, searches and study selection}

The article search was performed using bibliometric databases (MEDLINE, CINAHL, PsycInfo and ISI web of knowledge). Article inclusion criteria were (1) a population with GCA and (2) reporting a time-period of diagnostic delay between the onset of GCA symptoms and GCA diagnosis as an outcome. No restrictions were placed on language and authors were contacted to locate articles where necessary. Diagnosis of GCA could be defined by positive temporal artery biopsy, by American College of Rheumatology (ACR) 1990 criteria [21], or by a documented clinical diagnosis of GCA. Articles were excluded if patients did not have GCA or did not report diagnostic delay.

From the total number of articles identified through all searches, a single reviewer (HR) initially screened the articles by title. Two reviewers (HR \& JAP) independently screened articles by their abstracts and then, upon consensus, the remaining articles were reviewed in full (JAP \& CDM). Finally, the reference list of each included article was checked for further relevant articles by a single reviewer (JAP).

\section{Data extraction}

Data were extracted from eligible articles by two reviewers (JAP \& TH). The primary outcome of interest extracted from the final included articles was the mean time-period between onset of GCA symptoms and GCA diagnosis and the related estimate of variance. Other data extracted included lead author name, publication year, time-period between which patients were recruited or sampled from medical records, sample size, sex, age, country, healthcare setting, GCA-specific characteristic, method of GCA diagnosis, and how a delay in diagnosis had been defined. GCA-specific characteristics were examined within three categories, namely (1) commonlyreported GCA symptoms (polymyalgic symptoms, visual manifestation, visual loss, headache, jaw claudication and scalp tenderness); (2) subtype of GCA (cranial or non-cranial, presence or absence of PMR, positive or negative biopsy result); and (3) sample demographic (age, geographical location and sex).

\section{Quality assessment}

Two reviewers (JAP \& TH) assessed the quality of the final articles using a modified version of the NewcastleOttawa quality assessment scale for cohort studies. Though articles could be cross-sectional, case-control or cohort in design, several criteria were chosen from the cohort version of the Newcastle-Ottawa tool as this best represented the qualities required.

\section{Data synthesis}

The primary outcome of interest was the mean number of weeks between symptom onset and GCA diagnosis, with an accompanying estimate of variation (standard deviation (SD)); however, several articles reported data in other formats. Where possible, the corresponding author was contacted and data requested in the required format. Where data were not provided, data were converted to allow direct comparisons between datasets. Data conversion could occur in three instances, depending on the originally reported format. Firstly, if delay was reported in days or months, these values were converted to weeks. Secondly, if an article had reported the variance around a mean using a low to high range, then this was converted to a SD (using a formula from Hozo et al. [22], low to high range data was used to generate an imputed SD [23]). Thirdly, the SD for each dataset was converted to a standard error $(\mathrm{SD} / \sqrt{\mathrm{n}})$ for use in the meta-analysis.

\section{Analysis}

All articles included in the systematic review were initially examined using a narrative synthesis, comparing the characteristics of these articles. Random-effects meta-analysis was used to report a pooled mean number 
of weeks (95\% confidence interval (CI)) between symptom onset and GCA diagnosis. This meta-analysis was presented as a forest plot, with heterogeneity initially assessed using the $I^{2}$ statistic and then using 95\% prediction intervals (PI) as advocated by Riley et al. [24]; 95\% PIs may be added to summary results from randomeffects meta-analyses to illustrate heterogeneity of effects that may not be fully conveyed by the $95 \%$ CI. Where there is a wide distribution of effect estimates with little overlap in confidence intervals, 95\% PI can highlight a range of effects at the individual level across study settings and can prove more useful in clinical practice than a summary $I^{2}$ value.

Because the SD required imputation for several articles, sensitivity analyses were performed, firstly examining only those articles which originally reported SD, secondly only those articles which required imputation of SD, and thirdly those restricting GCA definition to biopsy-positive cases only. Finally, the extent of delay relating to GCA-specific characteristics was reported, with random-effects meta-analysis being conducted where there were a sufficient number of articles to do so.

\section{Results}

Search results

Out of 4128 articles initially identified, 141 were reviewed in full, leaving a total of 23 articles for inclusion. Of these, 11 were subsequently excluded as their datasets were duplicates of other articles. A further 10 additional articles were identified from reference lists. Therefore, 22 articles were included in the systematic review [11, 13, 20, 25-43], with 16 of these being pooled through meta-analysis $[11,13,20,26,28,30-33,36,37$, 39-43]. From these 16 articles, 9 included GCA-specific characteristic data $[11,13,28,30-32,37,41,43]$ and, when a further 6 previously excluded articles were reintroduced (articles using the same datasets now used in separate analyses), this totalled 15. Finally, 6 of these articles were included in the GCA-specific characteristic meta-analysis [11, 13, 28, 31, 41, 44] (Fig. 1).

\section{Sample characteristics}

Of the 22 articles included in the systematic review, 10 came from England or the US. Two articles included patients from primary care and 16 had a retrospective study design. The 22 articles comprised 2474 GCA patients, of whom $72 \%$ were female and the average age was 73 years (mean ages ranging from 63-79, excluding the outlier of $\mathrm{Hu}$ et al. [34], which was removed due to a far younger mean age (43 years) and predominantly male sample (15:1 ratio of males to females)). A total of 17 articles defined GCA by a positive temporal artery biopsy, with the remainder using clinical diagnosis or ACR criteria. None of the included articles had examined diagnostic delay of GCA as their primary question; there was little information on how delay data was collected (Table 1).

\section{Diagnostic delay of GCA}

The mean delay in receiving a diagnosis of GCA ranged from 1.2 (SD 1.6) to 34.7 (34.2) weeks. The majority of mean values had wide data ranges reported alongside them, with these often being skewed toward the higher value (Table 2). Five articles did not include all necessary data related to delay $[25,27,29,35,38]$ and that of $\mathrm{Hu}$ et al. [34] was excluded (Additional file 1: Table S1), leaving 16 articles included in the meta-analysis $[11,13$, $20,26,28,30-33,36,37,39-43]$.

The pooled mean time between GCA symptom onset and GCA diagnosis was 9.0 weeks (95\% CI, 6.5 to 11.4) $\left(I^{2}=96.0 \%, P<0.001\right)$ (Fig. 2). Sensitivity analysis showed minimal difference in the length of delay if only articles that reported the original SD (8.7 (5.1 to 12.3) weeks, $I^{2}=97.5 \%, P \leq 0.001$ ) (Additional file 1: Figure S1), imputed SD (9.1 (6.6 to 11.6) weeks, $I^{2}=84.6 \%, P \leq 0.001$ ) (Additional file 1: Figure S2), or those that had defined GCA through temporal artery biopsy (8.6 (5.6 to 11.5) weeks, $I^{2}=96.7 \% ; P \leq 0.001$ ) (Additional file 1: Figure S3) were included.

\section{GCA-specific characteristic diagnostic delay}

Nine articles included in the original meta-analysis also reported diagnostic delay for a particular GCA characteristic (Table 3). Six further articles [44-49] were reintroduced, their examination of GCA-specific characteristics meaning they could subsequently be compared against different datasets (Additional file 1: Table S2).

Five articles had specifically compared diagnostic delay for those with cranial versus non-cranial GCA. Cranial GCA was defined as presentation with cranial features (e.g. headache, scalp tenderness) or positive temporal artery biopsy. Non-cranial delay was defined as presentation of GCA with constitutional symptoms (e.g. fever, anorexia or polymyalgia) or other non-cranial presentation. Each included article had originally reported a significantly greater delay in those with non-cranial GCA compared with cranial GCA. Our meta-analysis demonstrated that those with cranial GCA received a diagnosis after 7.7 weeks (2.7 to $\left.12.8, I^{2}=98.4 \%, P<0.001\right)$ and those with non-cranial GCA after 17.6 weeks (9.7 to 25.5, $I^{2}=96.6 \%, P<0.001$ ) (Fig. 3).

No other characteristic had been reported often enough, included an appropriate comparator group or were from a unique dataset to allow further metaanalysis. However, within the original articles, significantly greater periods of delay had been reported in GCA patients without symptoms of headache compared to those with headache (16.6 vs. 9.2 weeks respectively, 


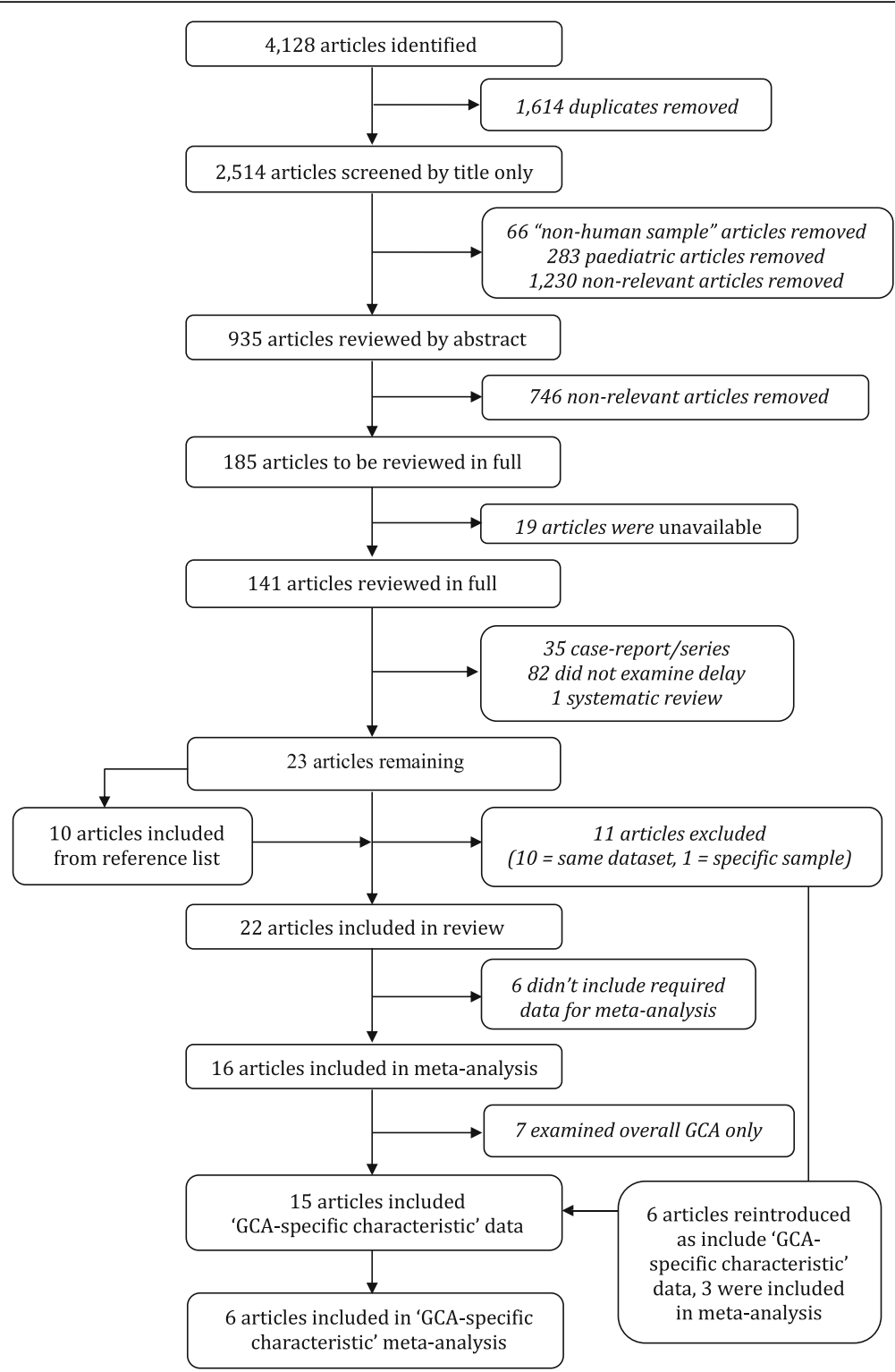

Fig. 1 Selection of articles for inclusion in systematic review and meta-analysis

$P \leq 0.001)$ [44], for those with GCA and PMR compared to GCA only (13.4 vs. 8.3 weeks, $P \leq 0.001$ ) [44], and for patients aged $\leq 69$ years compared to those aged $\geq 70$ (13.2 vs. 9.4 weeks, $P=0.03$ ) [49].

Additionally, 95\% PIs were calculated for each metaanalysis demonstrating an interval of 0 to 19.2 weeks for the mean time between symptom onset and GCA diagnosis (Fig. 2), 0 to 21.8 weeks for articles which reported SD only (Additional file 1: Figure S1), 1.0 to 17.2 weeks for those with imputed SD (Additional file 1: Figure S2), 0 to 20.2 weeks for articles where GCA had been defined through temporal artery biopsy (Additional file 1: Figure S3), 0 to 27.6 weeks for those with cranial symptoms
(Fig. 3), and 0 to 46.1 weeks for those with non-cranial symptoms (Fig. 3).

\section{Quality appraisal}

All articles included in the systematic review described samples broadly representative of GCA, based on age and sex distribution (except for Schmidt et al. [46]) and had ascertained the method of GCA diagnosis (typically temporal artery biopsy) from medical records (except for Pease et al. [37]). The majority of articles determined the time-period of diagnostic delay through review of medical records, as use of a retrospective cohort design was typical (Additional file 1: Table S3). Articles included in 

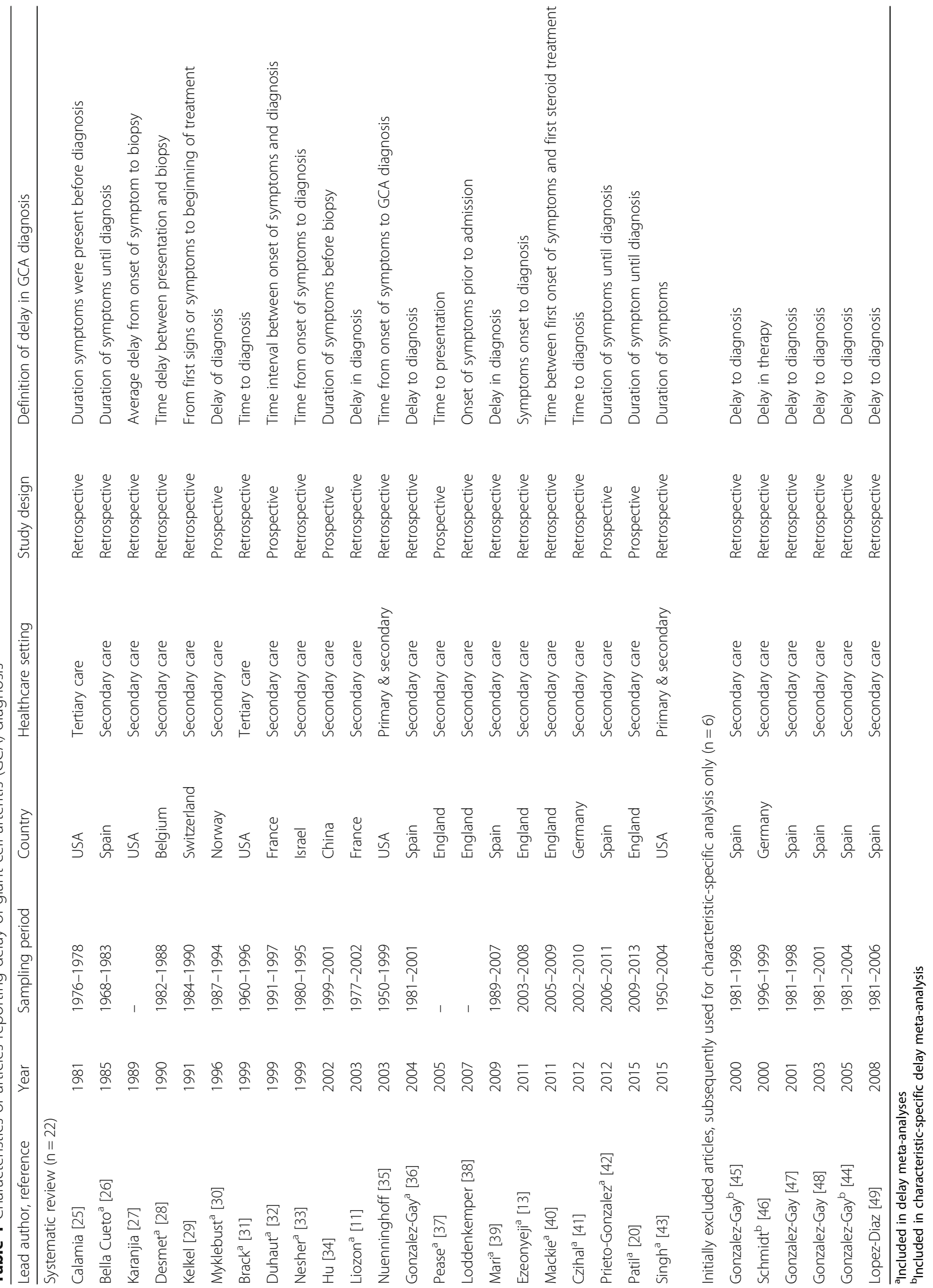

\section{$\frac{2 \pi}{\frac{\pi}{0}}$}

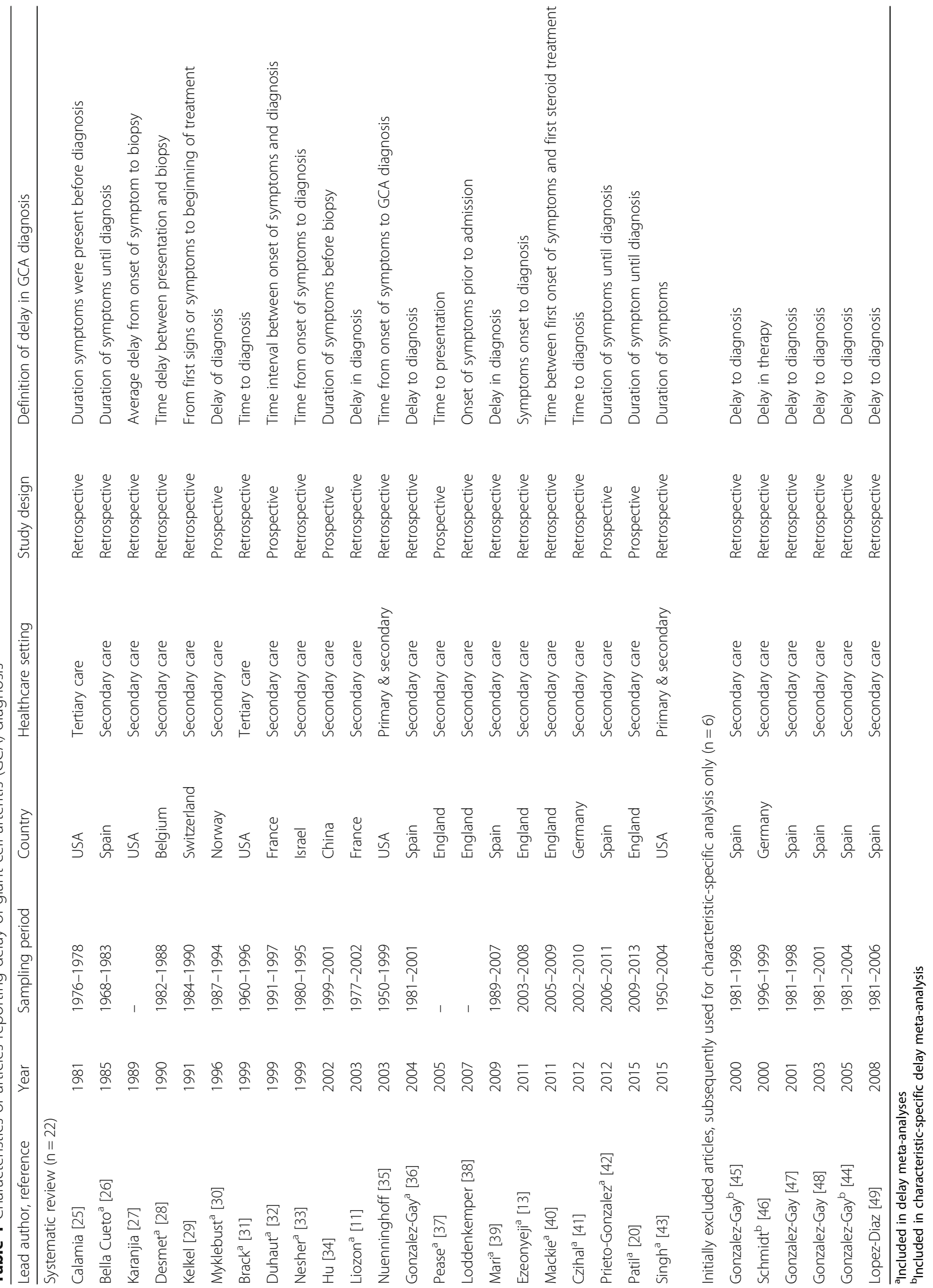

\section{줗}

过

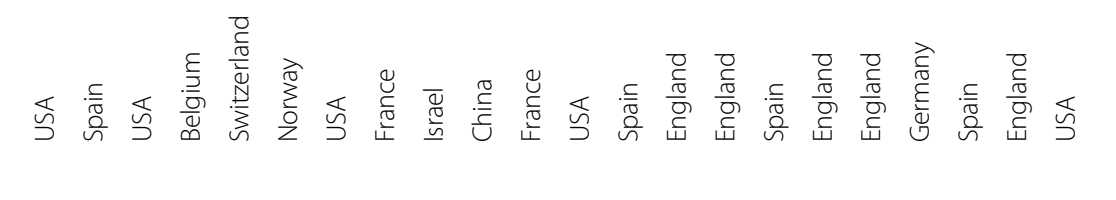

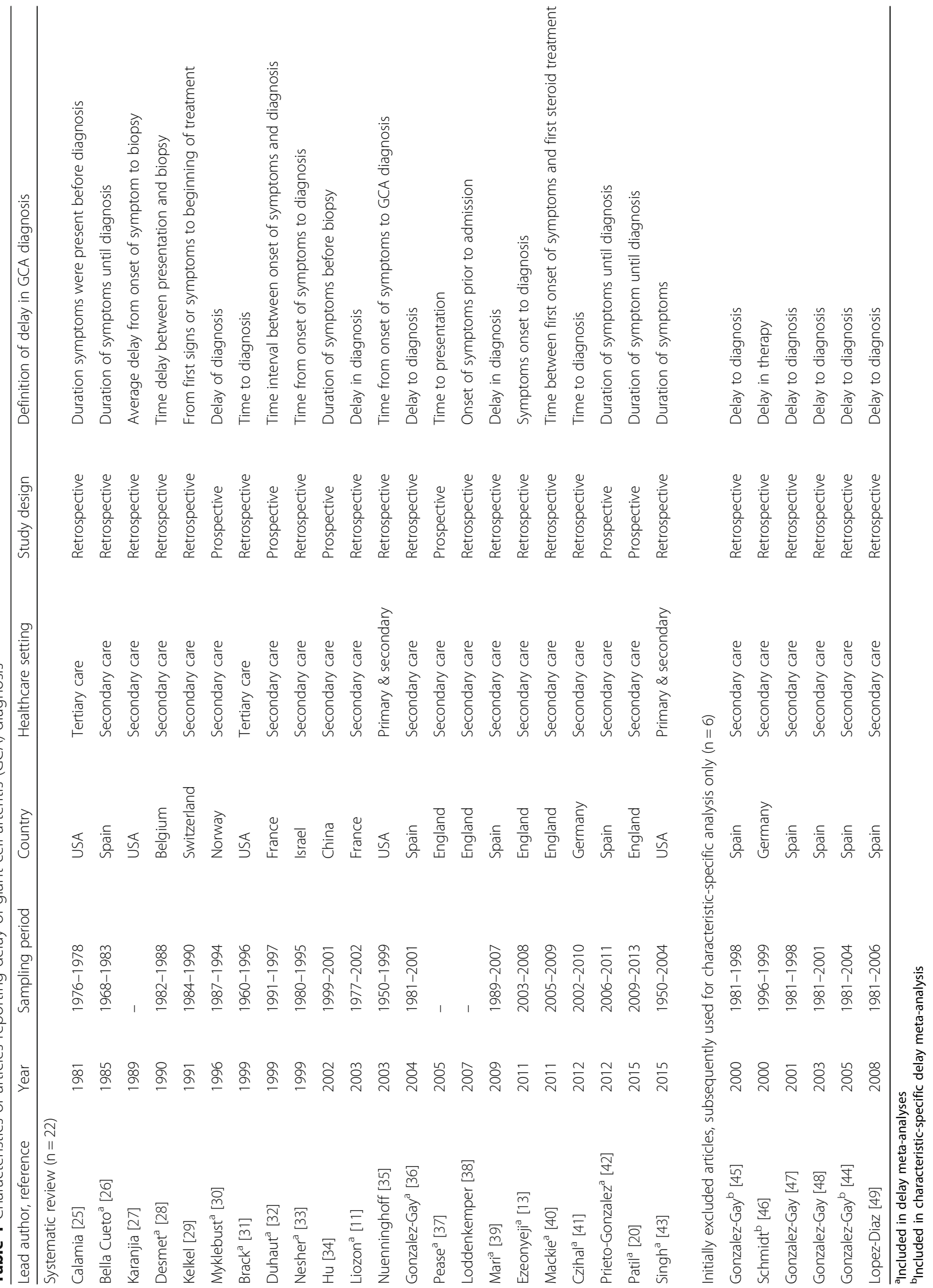

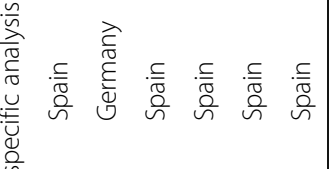

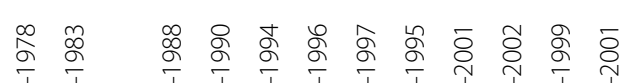

䓠 究

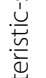
๙

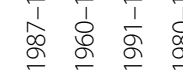
等

অ ஃ̊

א

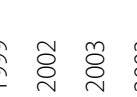
ลิ 


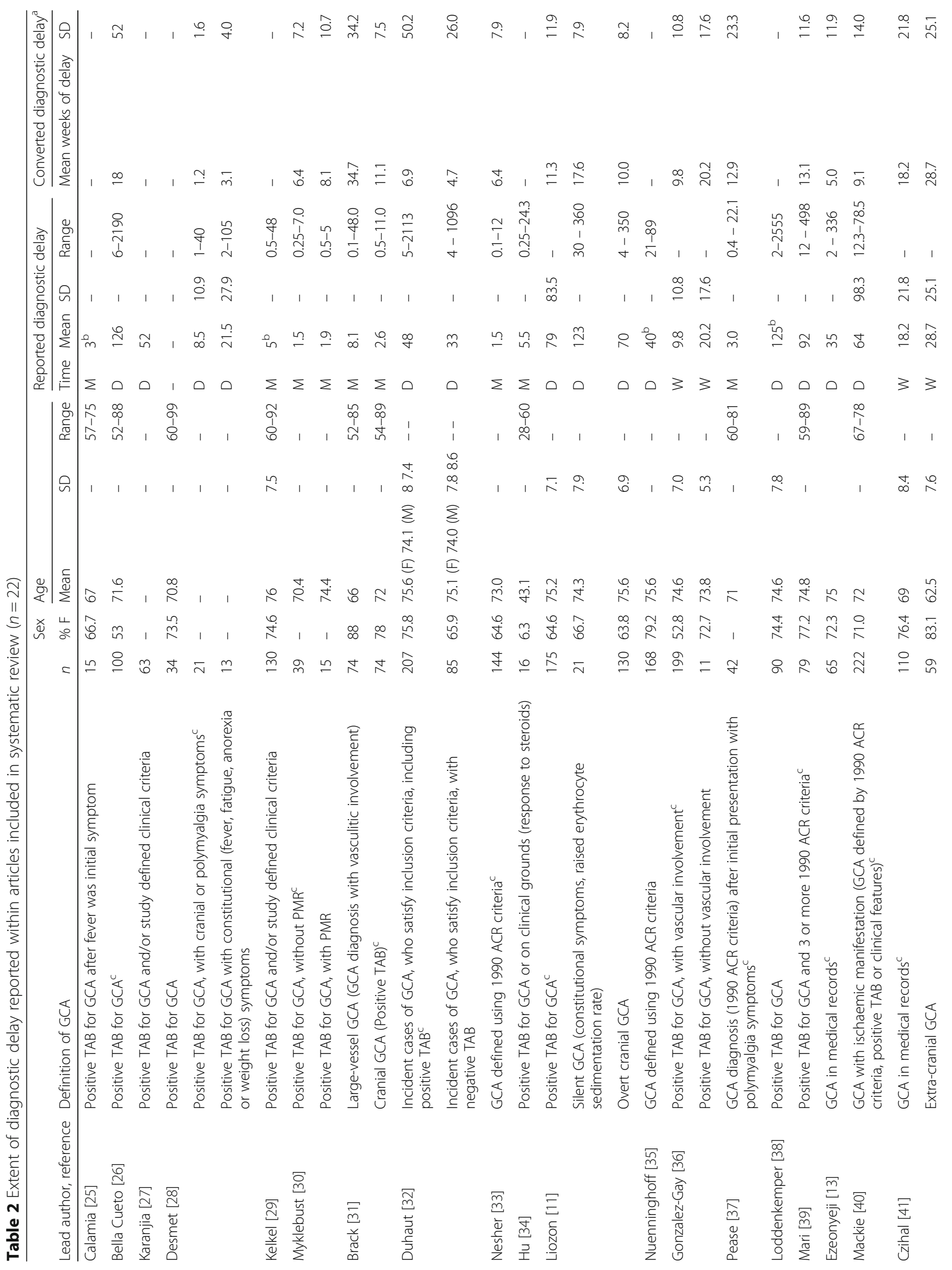




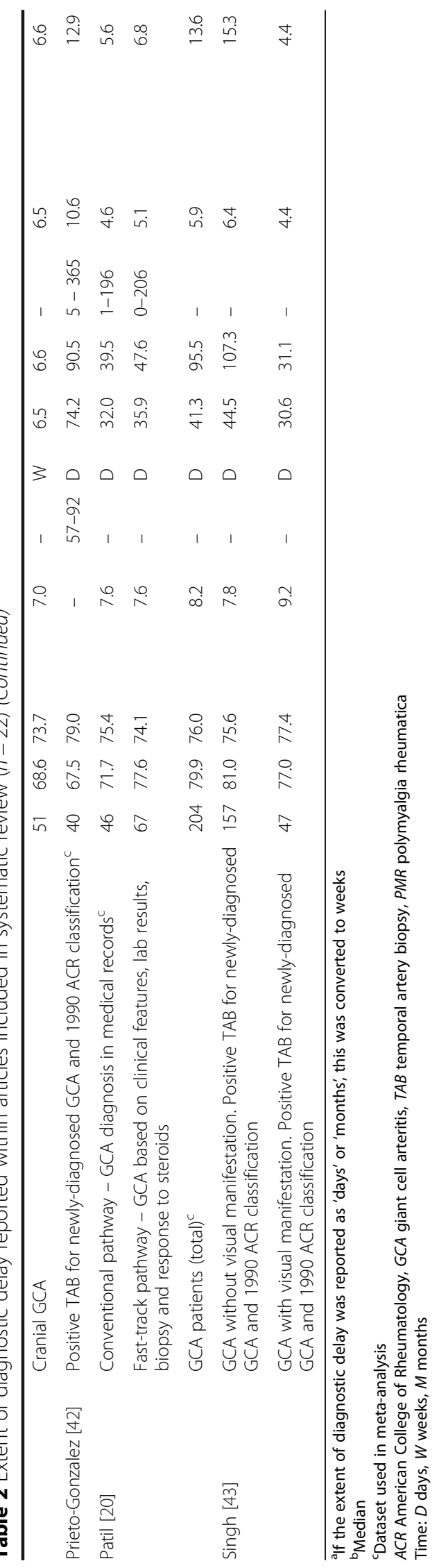




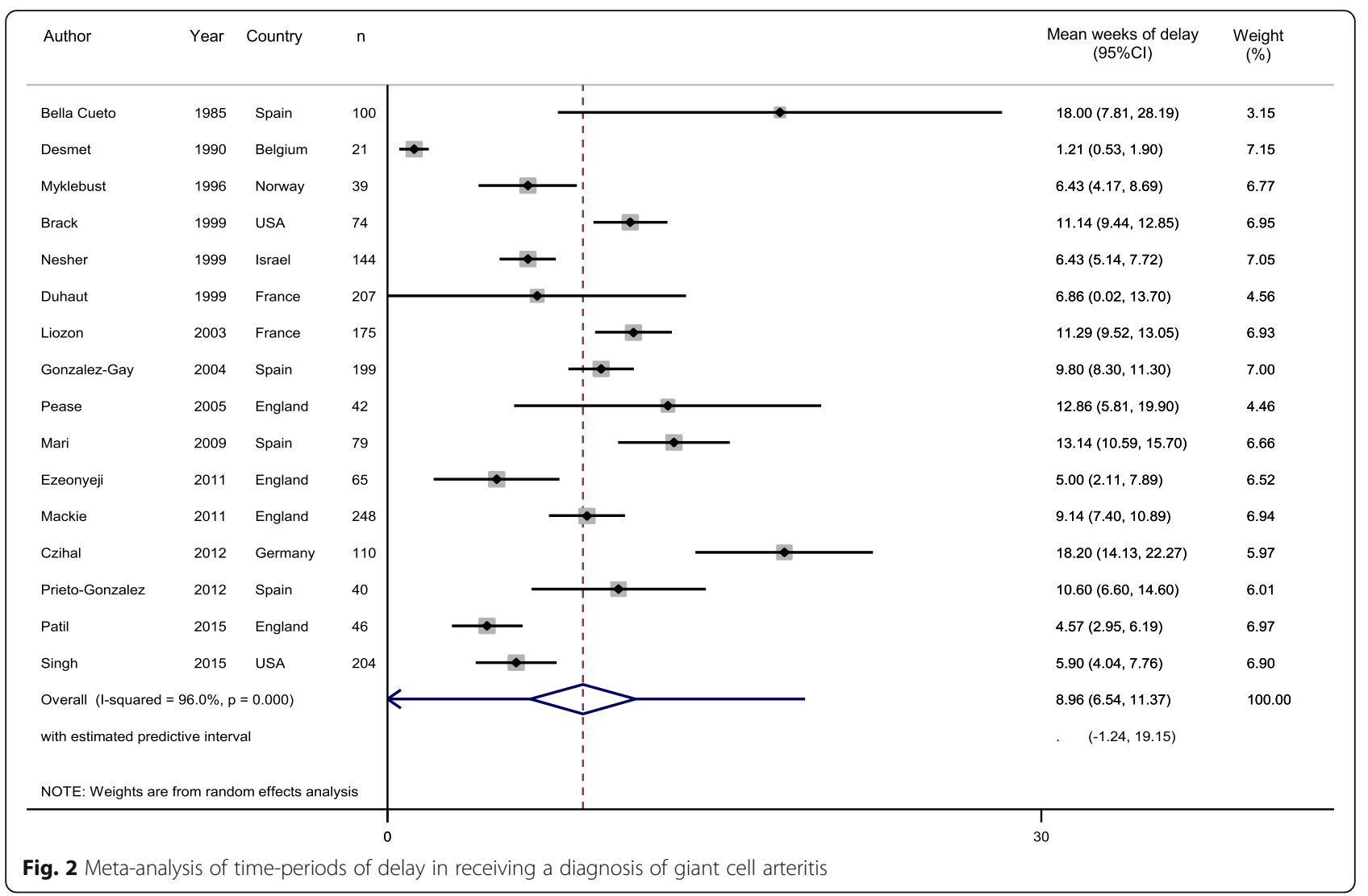

this review reported good quality of design, though little indication was provided on how delay was actually defined.

\section{Discussion}

This systematic review and meta-analysis examined the extent of delay between first experiencing symptoms related to GCA and receiving a confirmatory GCA diagnosis, finding the mean time-period of diagnostic delay to be 9 weeks. Also of interest was how diagnostic delay is influenced by GCA-specific characteristics. Here, we found that even when patients present with distinct cranial symptoms, the delay in finally receiving a GCA diagnosis remains substantial (8 weeks) and is longer still for those with non-cranial symptoms (18 weeks). Such findings are of concern, as previous research has reported that as few as half of GCA patients can experience temporal headaches [3].

Achieving a prompt and accurate diagnosis of GCA remains challenging, demonstrated by typically wide and skewed time-periods of delay within individual studies. It was not uncommon for time-periods of delay to range from a single day in one patient, to a year in another from the same study. Further research is needed to fully describe the characteristics of patients experiencing both short and long periods of delay. When a patient presents to the clinician with mainly constitutional symptoms, such as fever or malaise, diagnosis is more challenging as these symptoms are common and frequently occur in other, more prevalent disorders. However, patients who present with classic cranial GCA or typically associated symptoms (e.g. headache, PMR) still experience a prolonged period of diagnostic delay, highlighting the need for an increased awareness of all facets of this condition.

Diagnostic delay is a common problem in many conditions. For example, a median 9-week delay has been identified in diagnosing childhood brain tumours [50], and a 24-week median delay in rheumatoid arthritis (RA) [51]. As the delay in receiving a diagnosis for such conditions has been shown to have negative effects on outcomes, much research has looked to reduce this respective diagnostic delay. It remains unclear at what point(s) in the patient pathway the greatest potentially avoidable delay is incurred [52]. Raza et al. [51] examined the reasons for delay in assessment of RA across Europe. They found that delays in receiving a RA diagnosis could be related to the time taken for (1) the patient to consult healthcare after symptom onset, (2) the patient to be given an appointment, (3) the primary care clinician to refer the patients to secondary care, and (4) the patient to receive a secondary care appointment; the extent of delay at each point varied across countries. 
Table 3 Delay of giant cell arteritis (GCA) diagnosis by GCA-specific characteristic

\begin{tabular}{|c|c|c|c|c|c|c|c|}
\hline \multirow[b]{2}{*}{ Characteristics } & \multirow[b]{2}{*}{ Author } & \multirow[b]{2}{*}{ Year } & \multicolumn{4}{|c|}{ Mean delay by category } & \multirow[b]{2}{*}{$P$ value $^{a}$} \\
\hline & & & $\bar{n}$ & Weeks (SD) & $n$ & Weeks (SD) & \\
\hline \multicolumn{8}{|l|}{ Symptoms } \\
\hline \multirow[t]{3}{*}{ PMR } & & & & With & & Without & \\
\hline & Pease [37] & 2005 & 42 & $12.9(23.3)$ & - & - & - \\
\hline & Ezeonyeji [13] & 2011 & 14 & $6.0(1.8)$ & - & - & - \\
\hline \multirow[t]{4}{*}{ Visual manifestation } & & & & With & & Without & \\
\hline & Gonzalez-Gay [45] & 2000 & 42 & $9.6(11.3)$ & 119 & $11.5(12.5)$ & 0.19 \\
\hline & Ezeonyeji [13] & 2011 & 23 & $3.0(2.9)$ & - & - & - \\
\hline & Singh [43] & 2015 & 47 & $4.4(4.4)$ & 157 & $6.4(15.3)$ & - \\
\hline \multirow[t]{4}{*}{ Visual loss } & & & & With & & Without & \\
\hline & Gonzalez-Gay [45] & 2000 & 24 & $10.8(13.6)$ & 137 & $11.0(12.1)$ & 0.48 \\
\hline & Schmidt [46] & 2000 & 5 & $7(3)$ & - & - & - \\
\hline & Ezeonyeji [13] & 2011 & 16 & $1.7(1.4)$ & - & - & - \\
\hline \multirow[t]{3}{*}{ Headache } & & & & Yes & & No & \\
\hline & Gonzalez-Gay [44] & 2005 & 203 & $9.2(9.9)$ & 37 & $16.6(15.0)$ & $<0.001$ \\
\hline & Ezeonyeji [13] & 2011 & 54 & $4.3(3.9)$ & - & - & - \\
\hline \multirow[t]{2}{*}{ Jaw claudication } & & & & Yes & & No & \\
\hline & Ezeonyeji [13] & 2011 & 31 & $4.6(2.8)$ & - & - & - \\
\hline \multirow[t]{2}{*}{ Scalp tenderness } & & & & Yes & & No & \\
\hline & Ezeonyeji [13] & 2011 & 27 & $4.0(2.9)$ & - & - & - \\
\hline \multicolumn{8}{|l|}{ GCA } \\
\hline \multirow[t]{7}{*}{ Cranial vs. non-cranial } & & & & Cranial & & Non-cranial & \\
\hline & Desmet [28] & 1990 & 21 & $1.2(1.6)$ & 13 & $3.1(4.0)$ & $<0.05$ \\
\hline & Brack [31] & 1999 & 74 & $11.1(7.5)$ & 74 & $34.7(34.2)$ & $<0.001$ \\
\hline & Liozon [11] & 2003 & 130 & $10.0(8.2)$ & 21 & $17.6(7.9)$ & 0.003 \\
\hline & Gonzalez-Gay [44] & 2005 & 199 & $9.8(10.8)$ & 11 & $20.2(17.6)$ & 0.003 \\
\hline & Ezeonyeji [13] & 2011 & - & - & 21 & $5.4(3.5)$ & - \\
\hline & Czihal [41] & 2012 & 51 & $6.5(6.6)$ & 59 & $28.7(25.1)$ & $<0.01$ \\
\hline \multirow[t]{3}{*}{ GCA with PMR } & & & & GCA & & GCA \& PMR & \\
\hline & Myklebust [30] & 1996 & 39 & $6.4(7.2)$ & 15 & $8.1(10.7)$ & - \\
\hline & Gonzalez-Gay [44] & 2005 & 144 & $8.3(10.0)$ & 96 & $13.4(12.2)$ & $<0.001$ \\
\hline \multirow[t]{3}{*}{ Biopsy result } & & & & Positive & & Negative & \\
\hline & Duhaut [32] & 1999 & 207 & $6.9(50.2)$ & 85 & $4.7(26.0)$ & - \\
\hline & Gonzalez-Gay [47] & 2001 & 161 & $7(1.7)$ & 29 & $8(4.0)$ & 0.6 \\
\hline \multicolumn{8}{|l|}{ Demographic } \\
\hline \multirow[t]{2}{*}{ Age } & & & & $<69$ years & & $\geq 70$ years & \\
\hline & Lopez-Diaz [49] & 2008 & 46 & $13.2(12.8)$ & 227 & $9.4(10.2)$ & 0.03 \\
\hline \multirow[t]{2}{*}{ Location } & & & & Rural & & Urban & \\
\hline & Gonzalez-Gay [48] & 2003 & 132 & 9.9 (11.7) & 78 & $11.1(10.9)$ & 0.23 \\
\hline \multirow[t]{2}{*}{ Sex } & & & & Men & & Women & \\
\hline & Gonzalez-Gay [48] & 2003 & 97 & 9.7 (12.6) & 113 & $11.0(10.4)$ & 0.20 \\
\hline
\end{tabular}




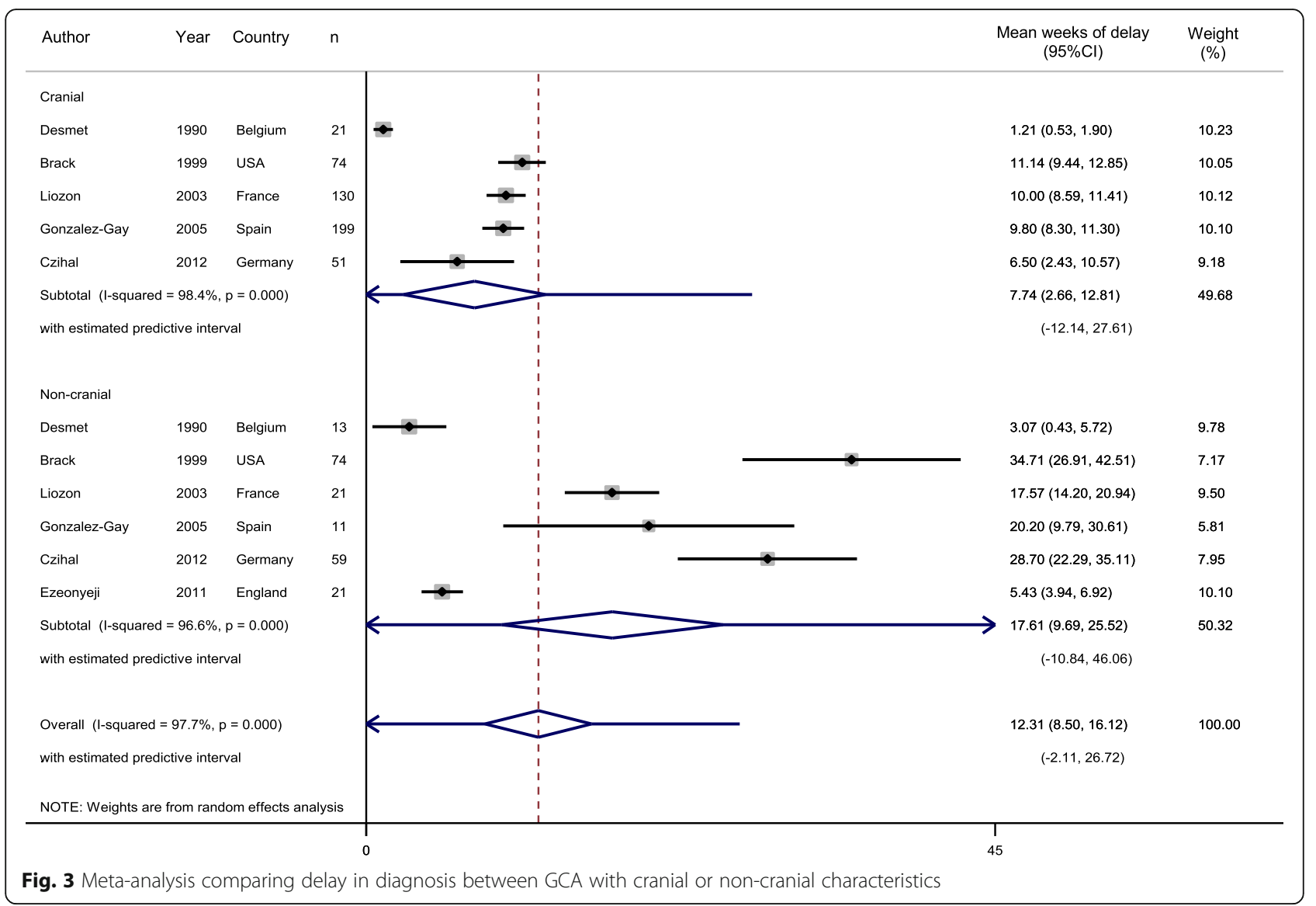

There may also be more specific reasons for delay, for example, varying test availability (i.e. ultrasonography) due to different service provision by geographical region or local funding allocation. Linked to variations in the point at which delay occurs, the terminology of delay should also be reconsidered. Future research should make the distinction between 'consultation delay' (the period from symptom onset to receiving a consultation) and 'diagnostic delay' (the time between first consultation and final diagnosis). This acknowledges that clinical diagnosis is not possible until the patient initiates contact with a health professional. Research has demonstrated that through disease awareness programmes it is possible to reduce delay at any stage of the disease pathway [19] and thus the importance of our review exists in determining an evidencebased baseline level of delay in GCA diagnosis that future studies must attempt to reduce.

The strength of this systematic review and metaanalysis is that it provides the first systematic approach to pool diagnostic delay of GCA in the world literature. We have also collated those articles that have examined delay related to specific GCA characteristics to identify barriers to receiving a prompt diagnosis.

The primary limitation of our research is that heterogeneity may have been introduced due to the way in which delay data were recorded. In each article, delay was a secondary outcome and little (or no) information was provided on how this information was obtained, for example, as part of routinely recorded clinical care (either contemporaneously or retrospectively) or whether patients were asked as part of the study protocol. However, as the majority of articles did define delay through the same phrasing (the time between GCA symptom onset and GCA diagnosis), the manner in which this was collected may be less important. Furthermore, though more detail on the mechanisms of delayed GCA diagnosis would be of great benefit, from the perspective of the patient or clinician, this is the best data that we presently have to understand the current issue of delay and therefore provides our best estimate to date.

Several articles report diagnostic delay data which is skewed. Though this may be considered as an influence on our final pooled values, standard meta-analytic methods assume normality in the distribution of the means (but not the raw data) and they are valid when sample sizes within individual studies are sufficient to enable the central limit theorem to hold. Related to the variance observed within articles, our meta-analyses reported high levels of heterogeneity. Though this is to be expected due to the high level of variance of delay 
reported, the study populations used in the metaanalyses were similar in the characteristics of age, proportion of females, two-thirds had defined GCA using a positive temporal artery biopsy (sensitivity analysis showed no difference in delay) and all but two patient samples were from secondary care. Despite this, it should be noted that data included in the meta-analysis did cover a wide time range (1950-2013), in which disease awareness and diagnostic methods will have varied. However, overall, we are confident that our metaanalysis, using reported mean values, provides the best estimate available of diagnostic delay in GCA patients.

\section{Conclusions}

Despite the reported time-period of diagnostic delay being considerably varied within some article samples, on average, patients experience a 9-week delay between the onset of their symptoms and receiving a diagnosis of GCA. Even when the patient has a 'classical' cranial presentation, delay remains considerable. In view of the potentially serious consequences of a missed GCA diagnosis, a reduction in diagnostic delay would be beneficial and could result in overall cost savings for healthcare systems [53]. Our research provides a new evidence-based benchmark of diagnostic delay of GCA against which future efforts to reduce this problem can be measured and supports the need for improved public awareness and fast-track diagnostic pathways.

\section{Additional file}

Additional file 1: Table S1. Characteristics of samples not-included in meta-analyses. Table S2. Characteristics of articles additionally included for giant cell arteritis (GCA)-specific characteristic analysis. Table S3. Article quality appraisal scores using the Newcastle-Ottawa Scale (NOS). Figure S1. Meta-analysis of time-periods of delay in receiving a diagnosis of GCA (Original SD only). Figure S2. Meta-analysis of time-periods of delay in receiving a diagnosis of GCA (Imputed SD only). Figure S3. Meta-analysis of time-periods of delay in receiving a diagnosis of GCA (GCA diagnosis through temporal artery biopsy only). (DOCX $70 \mathrm{~kb}$ )

\section{Abbreviations}

ACR: American College of Rheumatology; Cl: confidence intervals; GCA: giant cell arteritis; PI: prediction intervals; PMR: polymyalgia rheumatica; RA: rheumatoid arthritis; SD: standard deviation

\section{Acknowledgements}

Thanks are given to Keele staff that supported the study.

\section{Funding}

JP is funded through a Launching Fellowship by the NIHR School for Primary Care Research (SPCR), HR is funded through an INSPIRE Summer Studentship, coordinated by the Academy of Medical Sciences and funded by the Wellcome Trust, TH is funded by an NIHR Clinical Lectureship in General Practice, SLM is funded by a NIHR Clinician Scientist Fellowship award. CDM is funded by the NIHR Collaborations for Leadership in Applied Health Research and Care (CLAHRC) West Midlands, the NIHR SPCR, and a NIHR Research Professorship in General Practice (NIHR-RP-2014-04-026). The study sponsors had no role in study design, in the collection, analysis and interpretation of data, in the writing of the report, or in the decision to submit the paper for publication. The views and opinions expressed herein are those of the authors and do not necessarily reflect those of the NIHR (UK). This paper presents independent research which is part-funded by the CLAHRC West Midlands. The views expressed are those of the authors and not necessarily those of the NHS, the NIHR or the Department of Health.

Availability of data and materials

Not applicable.

\section{Authors' contributions}

Authors had access to all the study data, take responsibility for the accuracy of the analysis, and had authority over the manuscript and the decision to submit for publication. Guarantor of overall study integrity: JAP and CDM. Study concept and design: JAP, JL and CDM. Data collection and interpretation: JAP, HR, JB, SLM, TH, $J \mathrm{~L}$ and CDM. Statistical analysis: JAP and JB. Manuscript preparation: JAP, SLM, JB, $T H, J L$ and CDM. Final approval of manuscript: JAP, HR, SLM, JB, TH, JL and CDM. All authors read and approved the final manuscript.

\section{Competing interests}

The authors declare that they have no competing interests.

Ethics approval and consent to participate

Not applicable.

\section{Publisher's Note}

Springer Nature remains neutral with regard to jurisdictional claims in published maps and institutional affiliations.

\section{Author details}

${ }^{1}$ Research Institute for Primary Care and Health Sciences, Keele University, ST5 5BG Newcastle, UK. '²eeds Institute of Rheumatic and Musculoskeletal Medicine, University of Leeds, Leeds, UK. ${ }^{3}$ NIHR Leeds Musculoskeletal Biomedical Research Unit, Leeds, UK. Institute of Health and Society, Newcastle University, Newcastle, UK.

Received: 14 February 2017 Accepted: 9 May 2017

Published online: 28 June 2017

\section{References}

1. Smeeth L, Cook C, Hall AJ. Incidence of diagnosed polymyalgia rheumatica and temporal arteritis in the United Kingdom, 1990-2001. Ann Rheum Dis. 2006;65(8):1093-8

2. Hayreh SS, Podhajsky PA, Zimmerman B. Ocular manifestations of giant cell arteritis. Am J Ophthalmol. 1998;125(4):509-20.

3. Barraclough K, Mallen CD, Helliwell T, Hider SL, Dasgupta B. Diagnosis and management of giant cell arteritis. Br J Gen Pract. 2012;62(599):329-30.

4. Ponte C, Rodrigues AF, O'Neill L, Luqmani RA. Giant cell arteritis: Current treatment and management. World J Clin Cases. 2015:3(6):484-94.

5. Smith JH, Swanson JW. Giant cell arteritis. Headache. 2014;54(8):1273-89.

6. Robson JC, Kiran A, Maskell J, Hutchings A, Arden N, Dasgupta B, Hamilton W, Emin A, Culliford D, Luqmani RA. The relative risk of aortic aneurysm in patients with giant cell arteritis compared with the general population of the UK. Ann Rheum Dis. 2015;74(1):129-35.

7. Petri H, Nevitt A, Sarsour K, Napalkov P, Collinson N. Incidence of giant cell arteritis and characteristics of patients: Data-driven analysis of comorbidities. Arthritis Care Res. 2015;67(3):390-5

8. Nordborg E, Nordborg C. Giant cell arteritis: epidemiological clues to its pathogenesis and an update on its treatment. Rheumatology. 2003:42(3):413-21.

9. De Smit E, Palmer AJ, Hewitt AW. Projected worldwide disease burden from giant cell arteritis by 2050. J Rheumatol. 2015;42(1):119-25.

10. Aiello PD, Trautmann JC, McPhee TJ, Kunselman AR, Hunder GG. Visual prognosis in giant cell arteritis. Ophthalmology. 1993;100(4):550-5.

11. Liozon E, Boutros-Toni F, Ly K, Loustaud-Ratti V, Soria P, Vidal E. Silent, or masked, giant cell arteritis is associated with a strong inflammatory response and a benign short term course. J Rheumatol. 2003;30(6):1272-6.

12. Hellmann DB. Temporal arteritis: a cough, toothache, and tongue infarction. JAMA. 2002;287(22):2996-3000.

13. Ezeonyeji AN, Borg FA, Dasgupta B. Delays in recognition and management of giant cell arteritis: results from a retrospective audit. Clin Rheumatol. 2011;30(2):259-62 
14. Kennedy S. Polymyalgia rheumatica and giant cell arteritis: an in-depth look at diagnosis and treatment. J Am Acad Nurse Pract. 2012;24(5):277-85.

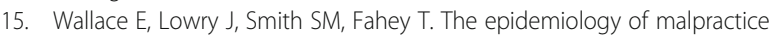
claims in primary care: a systematic review. BMJ Open. 2013;3(7):e002929.

16. Pattenden J, Watt I, Lewin RJ, Stanford N. Decision making processes in people with symptoms of acute myocardial infarction: qualitative study. BMJ. 2002;324(7344):1006-9.

17. Smith LK, Pope C, Botha JL. Patients' help-seeking experiences and delay in cancer presentation: a qualitative synthesis. Lancet. 2005;366(9488):825-31.

18. Gaspoz JM, Unger PF, Urban P, Chevrolet JC, Rutishauser W, Lovis C, Goldman L, Héliot C, Séchaud L, Mischler S, Waldvogel FA. Impact of a public campaign on pre-hospital delay in patients reporting chest pain. Heart. 1996;76(2):150-5.

19. Fry CW, Perrow R, Paul SP. Brain tumours in children: importance of early identification. Br J Nurs. 2014:23(22):1202-7.

20. Patil P, Williams M, Maw WW, Achilleos K, Elsideeg S, Dejaco C, Borg F, Gupta S, Dasgupta B. Fast track pathway reduces sight loss in giant cell arteritis: results of a longitudinal observational cohort study. Clin Exp Rheumatol. 2015;33(2 Suppl 89):S-103-6.

21. Hunder GG, Bloch DA, Michel BA, Stevens MB, Arend WP, Calabrese LH, Edworthy SM, Fauci AS, Leavitt RY, Lie JT. The American College of Rheumatology 1990 criteria for the classification of giant cell arteritis. Arthritis Rheum. 1990;33(8):1122-8.

22. Hozo SP, Djulbegovic B, Hozo I. Estimating the mean and variance from the median, range, and the size of a sample. BMC Med Res Methodol. 2005;5:13.

23. Furukawa TA, Barbui C, Cipriani A, Brambilla P, Watanabe N. Imputing missing standard deviations in meta-analyses can provide accurate results. J Clin Epidemiol. 2006;59(1):7-10.

24. Riley RD, Higgins JP, Deeks JJ. Interpretation of random effects metaanalyses. BMJ. 2011;342:d549.

25. Calamia KT, Hunder GG. Giant cell arteritis (temporal arteritis) presenting as fever of undetermined origin. Arthritis Rheum. 1981;24(11):1414-8.

26. Bella Cueto F, Costa Roma J, Gonzalez de Zarate P, Pujol Farriol R, Aguirre Errasti L, Martinez L de Letona J. Giant cell arteritis. Multicenter study of 100 cases with positive biopsies. Med Clin (Barc). 1985;85(2):43-8.

27. Karanjia ND, Giddings AE. Too few, too late. Temporal artery biopsy in cranial arteritis. J Cardiovasc Surg (Torino). 1989;30(6):882-4.

28. Desmet GD, Knockaert DC, Bobbaers HJ. Temporal arteritis: the silent presentation and delay in diagnosis. J Intern Med. 1990;227(4):237-40.

29. Kelkel E, Sarrot-Reynauld F, Dussud C, Pasquier D, Massot C. Belated diagnosis of temporal arteritis. Analysis of time elapsed before correct diagnosis in a retrospective study of 130 cases. Rev Med Interne. 1991;12(4):265

30. Myklebust G, Gran JT. A prospective study of 287 patients with polymyalgia rheumatica and temporal arteritis: clinical and laboratory manifestations at onset of disease and at the time of diagnosis. Br J Rheumatol. 1996;35(11):1161-8.

31. Brack A, Martinez-Taboada V, Stanson A, Goronzy JJ, Weyand CM. Disease pattern in cranial and large-vessel giant cell arteritis. Arthritis Rheum. 1999;42(2):311-7.

32. Duhaut $P$, Pinede L, Bornet $H$, Demolombe-Rague $S$, Dumontet $C$, Ninet J, Loire R, Pasquier J. Biopsy proven and biopsy negative temporal arteritis: differences in clinical spectrum at the onset of the disease. Groupe de Recherche sur l'Arterite a Cellules Geantes. Ann Rheum Dis. 1999;58(6):335-41.

33. Nesher G, Gur H, Ehrenfeld M, Rubinow A, Sonnenblick M. The changing clinical presentation of temporal arteritis in Israel: a multicenter study. Isr Med Assoc J. 1999;1(1):17-9.

34. Hu Z, Yang Q, Zeng S, Li J, Wu X, Cao L, Yang L, Song X. Giant cell arteritis in China: a prospective investigation. Angiology. 2002;53(4):457-63.

35. Nuenninghoff DM, Hunder GG, Christianson TJH, McClelland RL, Matteson EL. Incidence and predictors of large-artery complication (aortic aneurysm, aortic dissection, and/or large-artery stenosis) in patients with giant cell arteritis: A population-based study over 50 years. Arthritis Rheum. 2003:48(12):3522-31.

36. Gonzalez-Gay MA, Garcia-Porrua C, Amor-Dorado JC, Llorca J. Giant cell arteritis without clinically evident vascular involvement in a defined population. Arthritis Rheum. 2004;51(2):274-7.

37. Pease CT, Haugeberg G, Morgan AW, Montague B, Hensor EM, Bhakta BB. Diagnosing late onset rheumatoid arthritis, polymyalgia rheumatica, and temporal arteritis in patients presenting with polymyalgic symptoms. A prospective longterm evaluation. J Rheumatol. 2005;32(6):1043-6.
38. Loddenkemper T, Sharma P, Katzan I, Plant GT. Risk factors for early visual deterioration in temporal arteritis. J Neurol Neurosurg Psychiatry. 2007;78(11):1255-9.

39. Mari B, Monteagudo M, Bustamante E, Perez J, Casanovas A, Jordana R, Tolosa C, Oristrell J. Analysis of temporal artery biopsies in an 18-year period at a community hospital. Eur J Intern Med. 2009;20(5):533-6.

40. Mackie SL, Dasgupta B, Hordon L, Gough A, Green M, Hollywood J, Dutta S, Bejarano V, Jarrett S, Morgan AW, Pease CT. UK GCA Consortium: Ischaemic manifestations in giant cell arteritis are associated with area level socioeconomic deprivation, but not cardiovascular risk factors. Rheumatology (Oxford). 2011:50(11):2014-22.

41. Czihal M, Zanker S, Rademacher A, Tato F, Kuhlencordt PJ, Schulze-Koops H, Hoffmann U. Sonographic and clinical pattern of extracranial and cranial giant cell arteritis. Scand J Rheumatol. 2012;41(3):231-6.

42. Prieto-Gonzalez S, Arguis P, Garcia-Martinez A, Espigol-Frigole G, TaveraBahillo I, Butjosa M, Sanchez M, Hernandez-Rodriguez J, Grau JM, Cid MC. Large vessel involvement in biopsy-proven giant cell arteritis: prospective study in 40 newly diagnosed patients using CT angiography. Ann Rheum Dis. 2012;71(7):1170-6.

43. Singh AG, Kermani TA, Crowson CS, Weyand CM, Matteson EL, Warrington KJ. Visual manifestations in giant cell arteritis: trend over 5 decades in a population-based cohort. J Rheumatol. 2015:42(2):309-15.

44. Gonzalez-Gay MA, Barros S, Lopez-Diaz MJ, Garcia-Porrua C, SanchezAndrade A, Llorca J. Giant cell arteritis: disease patterns of clinical presentation in a series of 240 patients. Medicine (Baltimore). 2005:84(5):269-76

45. Gonzalez-Gay MA, Garcia-Porrua C, Llorca J, Hajeer AH, Branas F, Dababneh A, Gonzalez-Louzao C, Rodriguez-Gil E, Rodriguez-Ledo P, Ollier WE. Visual manifestations of giant cell arteritis. Trends and clinical spectrum in 161 patients. Medicine (Baltimore). 2000;79(5):283-92.

46. Schmidt D, Vaith P, Hetzel A. Prevention of serious ophthalmic and cerebral complications in temporal arteritis? Clin Exp Rheumatol. 2000;18(4 Suppl 20):S61-3

47. Gonzalez-Gay MA, Garcia-Porrua C, Llorca J, Gonzalez-Louzao C, RodriguezLedo P. Biopsy-negative giant cell arteritis: clinical spectrum and predictive factors for positive temporal artery biopsy. Semin Arthritis Rheum. 2001;30(4):249-56

48. Gonzalez-Gay MA, Garcia-Porrua C, Amor-Dorado JC, Llorca J. Influence of age, sex, and place of residence on clinical expression of giant cell arteritis in northwest Spain. J Rheumatol. 2003;30(7):1548-51.

49. Lopez-Diaz MJ, Llorca J, Gonzalez-Juanatey C, Pena-Sagredo JL, Martin J, Gonzalez-Gay MA. Implication of the age in the clinical spectrum of giant cell arteritis. Clin Exp Rheumatol. 2008;26(3 Suppl 49):S16-22.

50. Thulesius H, Pola J, Håkansson A. Diagnostic delay in pediatric malignancies - a population-based study. Acta Oncol. 2000;39(7):873-6.

51. Raza K, Stack R, Kumar K, Filer A, Detert J, Bastian H, Burmester GR, Sidiropoulos P, Kteniadaki E, Repa A, Saxne T, Turesson C, Mann H, Vencovsky J, Catrina A, Chatzidionysiou A, Hensvold A, Rantapää-Dahlqvist S, Binder A, Machold K, Kwiakowska B, Ciurea A, Tamborrini G, Kyburz D, Buckley CD. Delays in assessment of patients with rheumatoid arthritis: variations across Europe. Ann Rheum Dis. 2011;70(10):1822-5.

52. Scott SE, Walter FM, Webster A, Sutton S, Emery J. The model of pathways to treatment: conceptualization and integration with existing theory. $\mathrm{Br}$ J Health Psychol. 2013;18(1):45-65.

53. Patil P, Achilleos K, Williams M, Maw W, Dejaco C, Borg F, Gupta S, Dasgupta B. Outcomes and cost effectiveness analysis of fast track pathway in giant cell arteritis. Rheumatology (Oxford). 2014;53(suppl_2):i5-6. 